\title{
Halogen-substituted pyrazolo-pyrimidine derivatives as corrosion inhibitors for copper in sulfuric acid solution
}

\author{
Y. Xu, ${ }^{1}$ S. Zhang, ${ }^{1 *}$ L. Guo ${ }^{2 * *}$ B. Tan, ${ }^{1}$ C. Liao, ${ }^{1}$ Y. Zhou ${ }^{1}$ \\ and L.H. Madkour ${ }^{3}$ \\ ${ }^{I}$ School of Chemistry and Chemical Engineering, Chongqing University, \\ Chongqing 400044, China \\ ${ }^{2}$ School of Material and Chemical Engineering, Tongren University, \\ Tongren 554300, China \\ ${ }^{3}$ Chemistry Department, Faculty of Science and Arts, Al Baha University, \\ Baljarashi 65635, Saudi Arabia \\ E-mail:*stzhcq@163.com;**cqglei@163.com
}

\begin{abstract}
Sulfuric acid is widely used in several industrial fields, such as acid pickling, acid cleaning and acid descaling, which cause serious corrosion issues. Especially, copper being widely applied in industrial is vulnerable to be corroded by the acid. The usage of corrosion inhibitor is one of the most important techniques for controlling the corrosion. Several organic inhibitors containing hetero-atom, $\pi$-electrons and double bond have been applied for the corrosion inhibition of copper, which are found to exhibit high inhibiting properties by providing electrons to interact with metal surface. However, the use of several heterocyclic inhibitors has caused negative impact on the environment due to their toxicity and non-biodegradability. In this paper, pyrazolo-pyrimidine derivatives are found to attract great attention owing to their eco-friendly properties. Corrosion inhibited properties of three pyrazolo-pyrimidine derivatives namely 4-amino pyrazolo-pyrimidine (APP), 3-bromine 4-amino pyrazolo-pyrimidine (Br-APP) and 3-iodine 4-amino pyrazolo-pyrimidine (I-APP) on copper in $0.5 \mathrm{M} \mathrm{H}_{2} \mathrm{SO}_{4}$ solution were studied using electrochemical method and surface analysis techniques. Corrosion of copper has been largely inhibited by the inhibitors and the inhibited efficiency increase with the augment of concentration. The adsorption isotherms were simulated to explore the adsorption mode of inhibitors. Furthermore, theoretical calculations were applied to research the mechanism of inhibitors on copper.
\end{abstract}

Received: May 3, 2018. Published: June 7, 2018

doi: $\underline{10.17675 / 2305-6894-2018-7-2-9}$

Keywords: corrosion inhibitor, copper, electrochemical, molecular simulation, pyrazolo-pyrimidine. 


\section{Introduction}

Copper and its alloys have been applied to nearly every field of industries such as microelectronics, machinery and chemical industries [1]. However, copper is susceptible to be corroded in sulphuric acid solution that cause huge security issue and economic losses [2]. The addition of inhibitors is an effective and practical way to reduce the damage to copper [3]. Several organic compounds containing heteroatoms (nitrogen, oxygen, sulfur), polar functional groups, and conjugated double bonds are used as inhibitors for protecting copper in these years [4-7]. Benzotriazole (BTA) and its derivatives are the traditional inhibitors applied to decrease the corrosion of copper, but the BTA is toxic and may cause some environmental problem [8-10]. Therefore, it is necessary to find the effective and environment-friendly inhibitors.

Recently, pyrazolo-pyrimidine derivatives acting as promising inhibitors possessed many excellent performance and draw people's attention $[11,12]$. It has been reported that halogen substituted organics such as thiophenol [13], imidazoline [14], triazole [15], have already been proved to be good inhibitors. On the other hand, molecular simulation technique has played an increasingly significant role in the field of corrosion inhibitors [16-18]. Based on the above considerations, we will investigate the effect of halogen atoms on the inhibition performances of pyrazolo-pyrimidine.

Thus, the objective of current research is to study the inhibitive effectiveness of three kinds of pyrazolo-pyrimidine derivatives, i.e., 4-amino pyrazolo-pyrimidine (APP), 3-bromine 4-amino pyrazolo-pyrimidine (Br-APP) and 3-iodine 4-amino pyrazolopyrimidine (I-APP) on copper in sulphuric acid solution, which can provide basis for designing the molecular structure of the corrosion inhibitor. Electrochemical and surface analysis methods were employed. Additionally, we applied the density functional theory (DFT) calculations and molecular dynamics (MD) simulation to further explore their inhibition mechanism.

\section{Experimental}

\section{Materials preparation}

The $0.5 \mathrm{M} \mathrm{H}_{2} \mathrm{SO}_{4}$ solution was prepared with analytical grade $\mathrm{H}_{2} \mathrm{SO}_{4}(98 \%)$ in distilled water. The chemical structures of three investigated inhibitors are shown in Figure 1. They were purchased from Tansoole. Three kinds of inhibitors were added to $0.5 \mathrm{M} \mathrm{H}_{2} \mathrm{SO}_{4}$ solution to prepare solutions with four different concentrations $0.25,0.5,1$, and $4 \mathrm{mM}$, respectively. Experiments were conducted at indoor temperature of $298 \mathrm{~K}$ using thermostat-controlled water bath. Before performing the experiment, copper electrodes were polished with 800, 1200, and 2000 emery papers, then samples were washed with water, alcohol and finally dried at indoor temperature. 


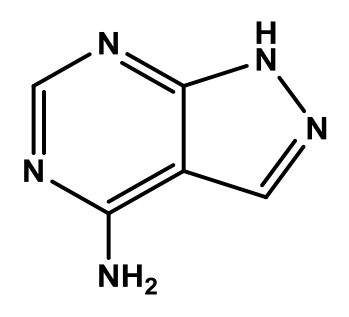

APP

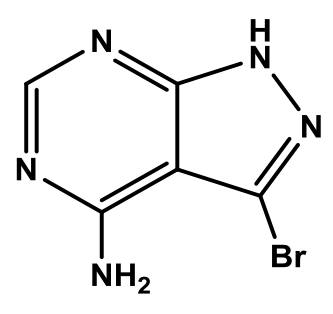

Br-APP

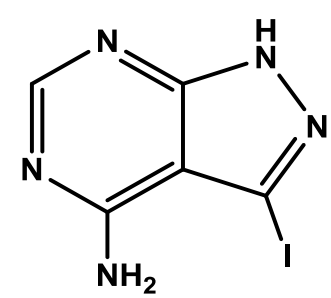

I-APP

Figure 1. The molecular structures of studied inhibitors.

\section{Electrochemical measurements}

Electrochemical tests were performed by using CHI604D electrochemical station with the conventional three-electro system, copper as the working electrode, a platinum electrode as the counter electrode, the saturated calomel electrode (SCE) as the reference electrode. All potentials were measured in the experiment versus the SCE. The EIS data were fitted by Zsimpwin 3.10 software.

Each test was performed three times to get satisfactory reproducibility. The open-circuit potential (OCP) was performed in test solution in $298 \mathrm{~K}$ until a steady-state was reached. Then the EIS experiment was measured at open circuit potential over a frequency range $100 \mathrm{kHz}-0.01 \mathrm{~Hz}$. Finally, polarization experiments were performed in the potential range of $\pm 250 \mathrm{mV}$ versus the OCP and the scan rate was set as $0.5 \mathrm{mV} \mathrm{s}^{-1}$.

\section{Scanning electron microscopy studies}

The morphology of the copper specimens before and after exposed in $0.5 \mathrm{M} \mathrm{H}_{2} \mathrm{SO}_{4}$ solution with and without inhibitors at $298 \mathrm{~K}$ were performed by field emission scanning electron microscope (FE-SEM, JEOL-JSM-7800F, JEOL Ltd, Japan) at high vacuum.

\section{Theoretical calculation details}

Quantum chemical calculations were performed using Gaussian 09 software. The molecular structures of three inhibitors were optimized by DFT using B3LYP functional with $6-311++\mathrm{G}(\mathrm{d}, \mathrm{p})$ basis set [19]. The quantum chemical parameters containing the energy of the lowest unoccupied molecular orbital $\left(E_{\mathrm{LUMO}}\right)$, the highest occupied molecular orbital $\left(E_{\mathrm{HOMO}}\right)$, energy gap $\left(\Delta E=E_{\mathrm{LUMO}}-E_{\mathrm{HOMO}}\right)$, and dipole moment $(\mu)$ were calculated. The adsorption mode of pyrazolo-pyrimidine derivatives on copper was investigated by conducting MD simulations using the Forcite module of Materials Studio software [20]. Accordingly, the densely packed $\mathrm{Cu}(111)$ surface model was chosen as representative because it is the most stable [21]. The interaction between the inhibitors and the $\mathrm{Cu}(111)$ surface was assumed in a simulation box $(2.2 \times 2.6 \times 4.3 \mathrm{~nm})$ using the COMPASS force field [22] with periodic boundary conditions. A simulation temperature of $298 \mathrm{~K}$ and NVT 
canonical ensemble with a timestep of $1 \mathrm{fs}$ and simulation time of $500 \mathrm{ps}$ were implemented in all MD simulations.

\section{Results and discussion}

\section{Potentiodynamic polarization curves}

The polarization curves of copper in $0.5 \mathrm{M} \mathrm{H}_{2} \mathrm{SO}_{4}$ solution with and without APP, Br-APP, I-APP are displayed in Figure 2a, 2b, and 2c, respectively. The Tafel slope values of anodic and cathodic indicates that both the anodic and cathodic reactions were suppressed with the addition of inhibitors. In addition, the Tafel slops of cathodic curves did not change apparently, indicating that the mechanism of the cathodic reaction cannot be changed in the presence of pyrazolo-pyrimidine derivatives [23]. And all the anodic curves presented current plateaus, which were ascribed to the reduction of the oxygen dissolved in solution [24]. The current plateaus of I-APP are broader than APP and Br-APP. At the same time, the anodic curves of APP have slightly variation compared to blank, manifesting APP did not change the mechanism of anodic reaction. However, it can be seen from the Figure $2 b$ that the slope variations for inhibited solutions indicated a change in the corrosion mechanism of copper. From the Figure 2c, the anodic curves of I-APP have more variation. The current plateaus are broader than the other two, manifesting more adsorbate and better inhibited effect.

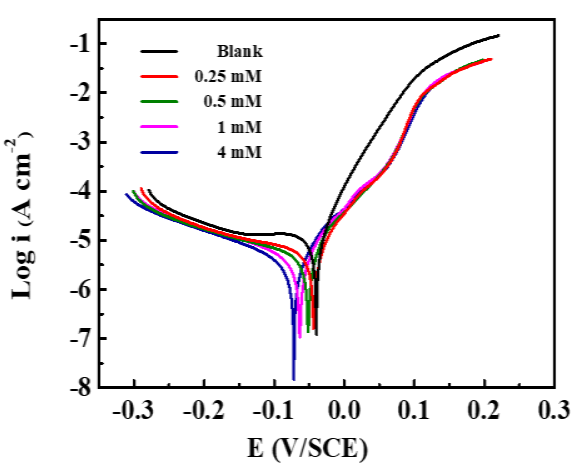

(a)

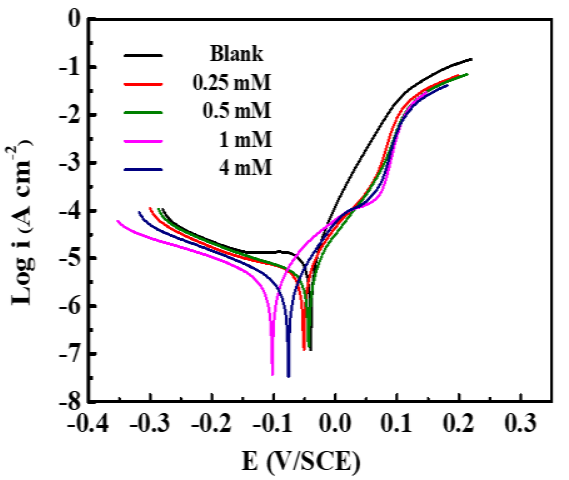

(b)

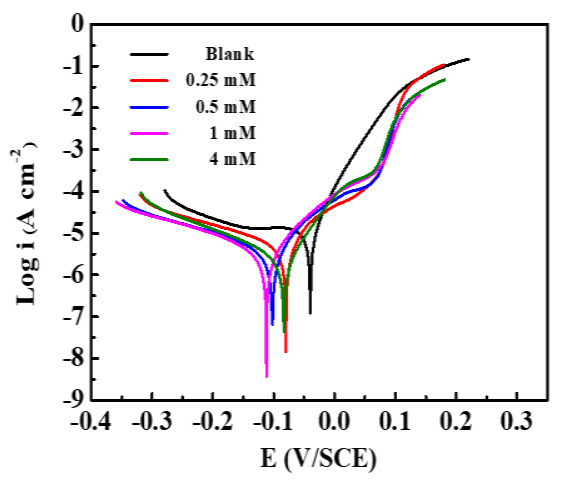

(c)

Figure 2. Tafel polarization curves for copper obtained in $0.5 \mathrm{M} \mathrm{H}_{2} \mathrm{SO}_{4}$ containing different concentrations of (a) APP, (b) Br-APP, and (c) I-APP.

The electrochemical corrosion parameters containing corrosion potentials $\left(E_{\text {corr }}\right)$, corrosion currents densities $\left(i_{\text {corr }}\right)$, anodic Tafel slopes $\left(\beta_{\mathrm{a}}\right)$, and cathodic Tafel slopes $\left(\beta_{\mathrm{c}}\right)$ have been got from the polarization curves by the Tafel extrapolation, and the values are displayed in Table 1 . The inhibition efficiency $(\eta)$ values listed in Table 1 were obtained by using the following equation: 


$$
\eta=\frac{i_{\text {corr }, 0}-i_{\text {corr }}}{i_{\text {corr }, 0}} \times 100
$$

where $i_{\text {corr }}$ and $i_{\text {corr }, 0}$ denote the corrosion current densities in the presence or absence of inhibitors, respectively.

As is shown in Table 1, all the potential displaced to more negative potential compared to the blank, and the movement of $E_{\text {corr }}$ were less than $85 \mathrm{mV}$. This result reveals that pyrazolo-pyrimidine derivatives are mixed-type inhibitors $[25,26]$. In addition, the $i_{\text {corr }}$ values decrease with the increase of concentration, which reveal the increase of inhibited efficiency. It is obviously that the efficiency of inhibitors follows I-APP $>$ Br-APP $>$ APP.

Table 1. Polarization data and corresponding inhibition efficiency for copper obtained in $0.5 \mathrm{M} \mathrm{H}_{2} \mathrm{SO}_{4}$ solution with and without addition of different concentrations of studied inhibitors.

\begin{tabular}{ccccc}
\hline Species & $\boldsymbol{C}(\mathbf{m M})$ & $\boldsymbol{E}_{\text {corr }}(\mathbf{m V})$ & $\boldsymbol{i}_{\text {corr }}\left(\boldsymbol{\mu A ~ \mathbf { ~ c m } ^ { - 2 } )}\right.$ & $\boldsymbol{\eta}(\boldsymbol{\%})$ \\
\hline \multirow{3}{*}{ APP } & Blank & -40 & 14.4 & - \\
& 0.25 & -44 & 7.96 & 44.8 \\
& 0.5 & -52 & 6.73 & 53.3 \\
& 1 & -63 & 5.15 & 64.3 \\
Br-APP & 4 & -72 & 4.19 & 70.9 \\
& 0.25 & -51 & 7.31 & 49.2 \\
& 0.5 & -43 & 5.96 & 58.6 \\
& 1 & -102 & 4.14 & 71.3 \\
I-APP & 4 & -76 & 3.37 & 76.6 \\
& 0.25 & -80 & 6.82 & 52.6 \\
& 0.5 & -102 & 4.29 & 70.2 \\
& 1 & -112 & 3.89 & 73.0 \\
& 4 & -83 & 2.73 & 81.0 \\
\hline
\end{tabular}

\section{Impedance measurements}

Figure 3 present the Nyquist plots of copper in $0.5 \mathrm{M} \mathrm{H}_{2} \mathrm{SO}_{4}$ with the absence and presence of studied inhibitors at various concentrations. For blank, the impedance spectra showed a Warburg impedance containing a capacitive loop in the high frequency region and following a straight line in low frequency. The high frequency capacitive loop is related to the charge transfer resistance [27, 28]. The low frequency straight line indicates that the corrosion process involves the transport of inhibitors from the bulk solution to the copper/solution interface [29]. The Warburg impedance is related to the diffusion of dissolved oxygen [30]. 
In Figure 3a, the shape of inhibited curves is similar with the uninhibited ones, revealing that the addition of APP increases the impedance but did not change other electrochemical traits of the solution. However, Warburg impedance disappears at $4 \mathrm{mM}$ of Br-APP, indicating the higher protection for copper. For Figure 3c, all the impedance curves displayed a depressed capacitive loop without Warburg impedance, which reveal that the diffusion process was strongly blocked by the I-APP [31]. At the same time, the diameter of Nyquist plots increases with the increase of concentration, indicating that the protection for copper becomes stronger as the concentration increases.

(a)

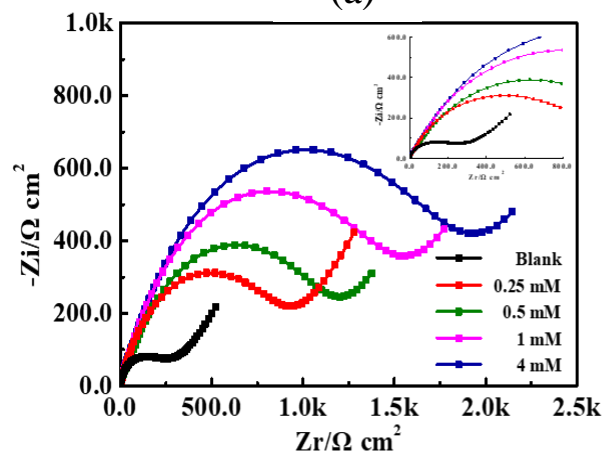

(b)

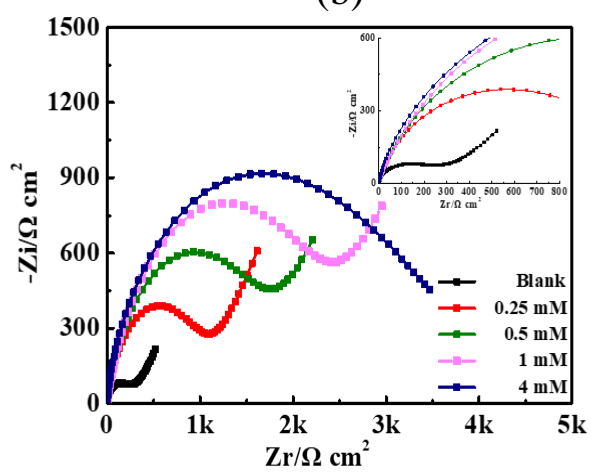

(c)

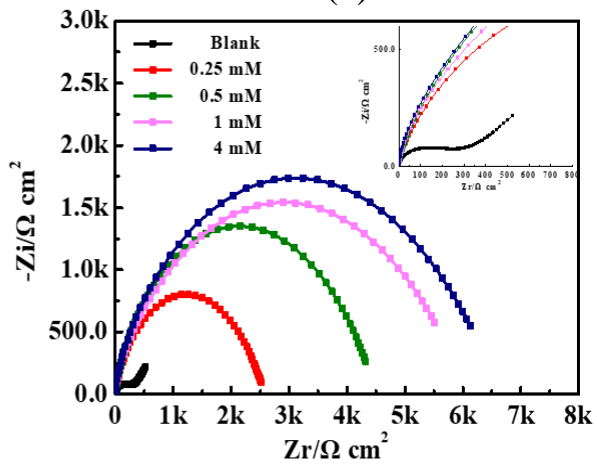

Figure 3. Nyquist impedance diagrams for copper in $0.5 \mathrm{M} \mathrm{H}_{2} \mathrm{SO}_{4}$ with and without different concentration of (a) APP, (b) Br-APP, and (c) I-APP.

Figure 4 shows the Bode plots of three kinds of inhibitors. The low-frequency impedance value increases up to two orders of magnitude compared to the solution without inhibitors, indicating the high inhibited effect of the inhibitors [32]. It is obviously that the frequency range with the maximum phase angle increases with the increasing concentration of inhibitors in the solution, demonstrating effective adsorption of inhibitor molecules on the copper surface [33].

(a)

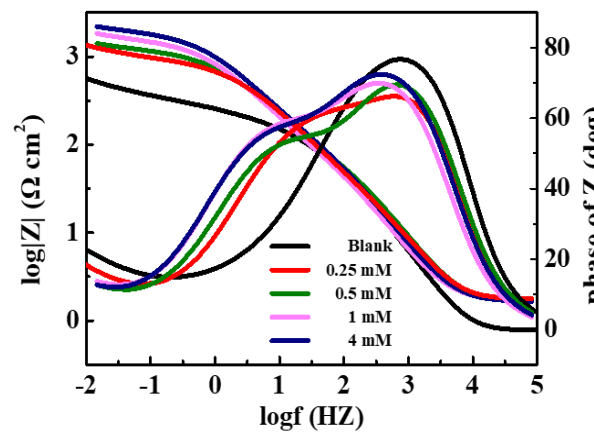

(b)

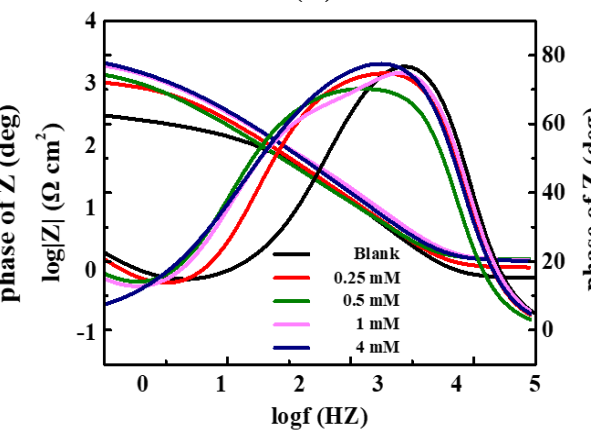

(c)

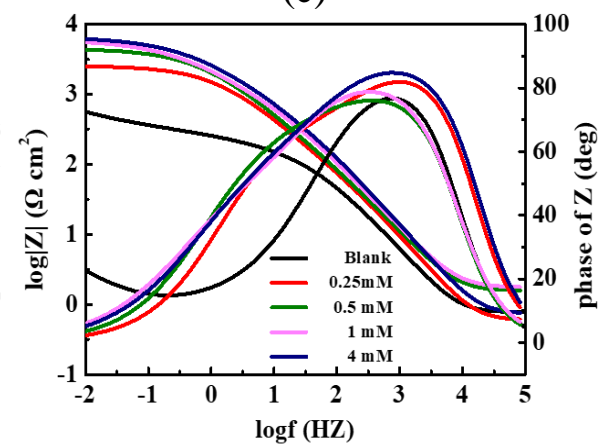

Figure 4. Bode plots and phase angle of copper in $0.5 \mathrm{M} \mathrm{H}_{2} \mathrm{SO}_{4}$ in the absence and presence of (a) APP, (b) Br-APP, and (c) I-APP. 
Figure 5 gives two kinds of equivalent circuits. The impedance spectra involving Warburg impedance were fitted using the equivalent circuit displayed in Figure 5a. Another that in Figure $5 \mathrm{~b}$ was applied to analyze the impedance spectra without impedance spectra. Herein, $R_{\mathrm{s}}$ means the solution resistance, $R_{\mathrm{f}}$ is the resistance of protective inhibitor film formed on copper surface, $R_{\mathrm{ct}}$ means the charge transfer resistance, and $W$ is the Warburg impedance. $\mathrm{CPE}_{\mathrm{dl}}$ and $\mathrm{CPE}_{\mathrm{f}}$ are constant phase angle elements, representing double layer capacitance $\left(C_{\mathrm{dl}}\right)$ and film capacitance $\left(C_{\mathrm{f}}\right)$, respectively. The impedance of CPE is calculated as follows [34,35]:

$$
Z_{\mathrm{CPE}}=\frac{1}{Y_{0}(j \omega)^{n}}
$$

From the equation, $Y_{0}$ is the magnitude of the CPE, $\omega$ is the angular frequency, $j$ is the imaginary root, and $n$ is the deviation parameter regarding phase shift. If $n=0$, the CPE is same as a pure resistor, and for $n=1$, a pure capacitor.

(a)

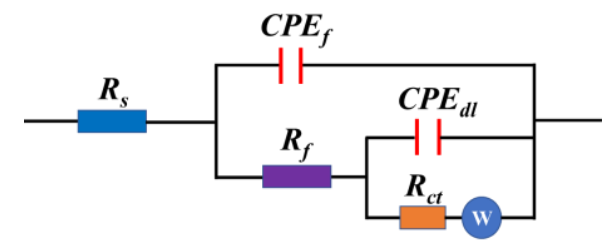

(b)

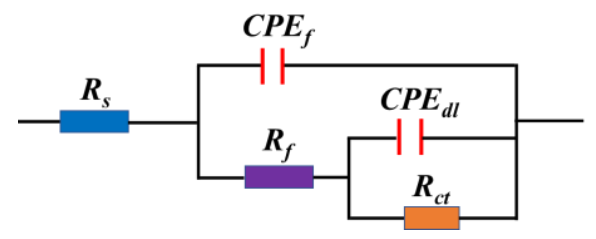

Figure 5. Electrochemical equivalent circuits used to fit the experiment data.

The impedance data got from above equivalent circuits are listed in Table 2. The inhibited efficiency of pyrazolo-pyrimidine derivatives is calculated from the charge transfer resistance $R_{\mathrm{ct}}$ according to equation (3), where $R_{\mathrm{ct}}$ and $R_{\mathrm{ct}, 0}$ are the charge transfer resistance of the copper electrode in the presence and absence of pyrimidine derivatives, respectively.

$$
\eta=\frac{R_{\mathrm{ct}}-R_{\mathrm{ct}, 0}}{R_{\mathrm{ct}}} \times 100
$$

It can be seen from Table 2 that $R_{\mathrm{ct}}$ increases with the increase of concentration, indicating the inhibitors adsorption film formed on the copper surface and prevented the charge transfer [36]. At the same time, $C_{\mathrm{dl}}$ decreases due to more protection on electrode surface. As a result, inhibited efficiencies displayed an increasing trend with the growth of inhibitors concentration, and the values are 78\% for APP, $89 \%$ for Br-APP, 94\% for I-APP at the highest concentration, respectively. The inhibited efficiencies follow I-APP $>$ Br-APP $>$ APP, which confirmed the result of polarization measurements. 
Table 2. Electrochemical parameters of impedance and corresponding inhibition efficiency for copper obtained in $0.5 \mathrm{M} \mathrm{H}_{2} \mathrm{SO}_{4}$ solution with and without addition of different concentration of studied inhibitors.

\begin{tabular}{|c|c|c|c|c|c|c|c|c|c|}
\hline Species & $\underset{(\mathbf{m M})}{C}$ & $\begin{array}{c}R_{\mathrm{S}} \\
\left(\Omega \mathrm{cm}^{2}\right)\end{array}$ & $\begin{array}{c}R_{\mathrm{ct}} \\
\left(\mathbf{k} \boldsymbol{\Omega} \mathbf{c m}^{2}\right)\end{array}$ & $\begin{array}{c}C_{\mathrm{f}} \\
\left(\times 10^{-5} \mathrm{~F} \mathrm{~cm}^{-2}\right)\end{array}$ & $n_{1}$ & $\begin{array}{c}C_{\mathrm{dl}} \\
\left(\times 10^{-5} \mathrm{~F} \mathrm{~cm}^{-2}\right)\end{array}$ & $n_{2}$ & $W$ & $\eta(\%)$ \\
\hline & Blank & 0.67 & 0.41 & 87.7 & 0.35 & 2.43 & 1 & 12 & - \\
\hline \multirow{4}{*}{ APP } & 0.25 & 1.74 & 0.92 & 2.90 & 0.95 & 17.11 & 0.67 & 7.0 & 55 \\
\hline & 0.5 & 1.66 & 1.17 & 3.02 & 0.94 & 19.97 & 0.70 & 8.9 & 65 \\
\hline & 1 & 1.69 & 1.50 & 5.32 & 0.92 & 17.05 & 0.72 & 6.5 & 73 \\
\hline & 4 & 1.64 & 1.88 & 4.07 & 0.93 & 15.64 & 0.70 & 6.1 & 78 \\
\hline \multirow{4}{*}{ Br-APP } & 0.25 & 1.13 & 1.08 & 2.19 & 1 & 12.04 & 0.66 & 4.8 & 62 \\
\hline & 0.5 & 1.54 & 1.76 & 2.33 & 0.99 & 16.40 & 0.68 & 4.9 & 77 \\
\hline & 1 & 1.45 & 2.42 & 1.99 & 0.97 & 11.38 & 0.65 & 4.1 & 83 \\
\hline & 4 & 1.58 & 3.62 & 1.66 & 0.98 & 10.25 & 0.68 & - & 89 \\
\hline \multirow{4}{*}{ I-APP } & 0.25 & 0.60 & 2.58 & 1.65 & 1 & 10.69 & 0.63 & - & 84 \\
\hline & 0.5 & 1.58 & 4.51 & 1.24 & 1 & 9.12 & 0.62 & - & 91 \\
\hline & 1 & 1.74 & 6.09 & 2.12 & 0.94 & 12.76 & 0.55 & - & 93 \\
\hline & 4 & 0.74 & 6.66 & 1.15 & 1 & 9.26 & 0.56 & - & 94 \\
\hline
\end{tabular}

\section{SEM analysis}

Figure $6 \mathrm{a} \sim 6 \mathrm{~d}$ shows the micrographs of the copper specimens exposed to $0.5 \mathrm{M} \mathrm{H}_{2} \mathrm{SO}_{4}$ solution for $32 \mathrm{~h}$ in the absence and presence of $4 \mathrm{mM}$ APP, Br-APP and I-APP, respectively. The copper surface without pyrazolo-pyrimidine derivatives is severely destroyed by the aggressive solution, as is shown in Figure 6a. The corrosion of copper is reduced in Figure $6 \mathrm{~b}$ after adding inhibitors due to the protection of organics. Figure $6 \mathrm{c}$ shows that the copper surface is protected by Br-APP and is smoother than Figure 6b. At the same time, Figure 6d reflects the stronger protection of I-APP on copper than APP and Br-APP. Therefore, it can be concluded that the corrosion of copper is inhibited in the presence of inhibitors and the inhibited sequence follows I-APP > Br-APP > APP. 

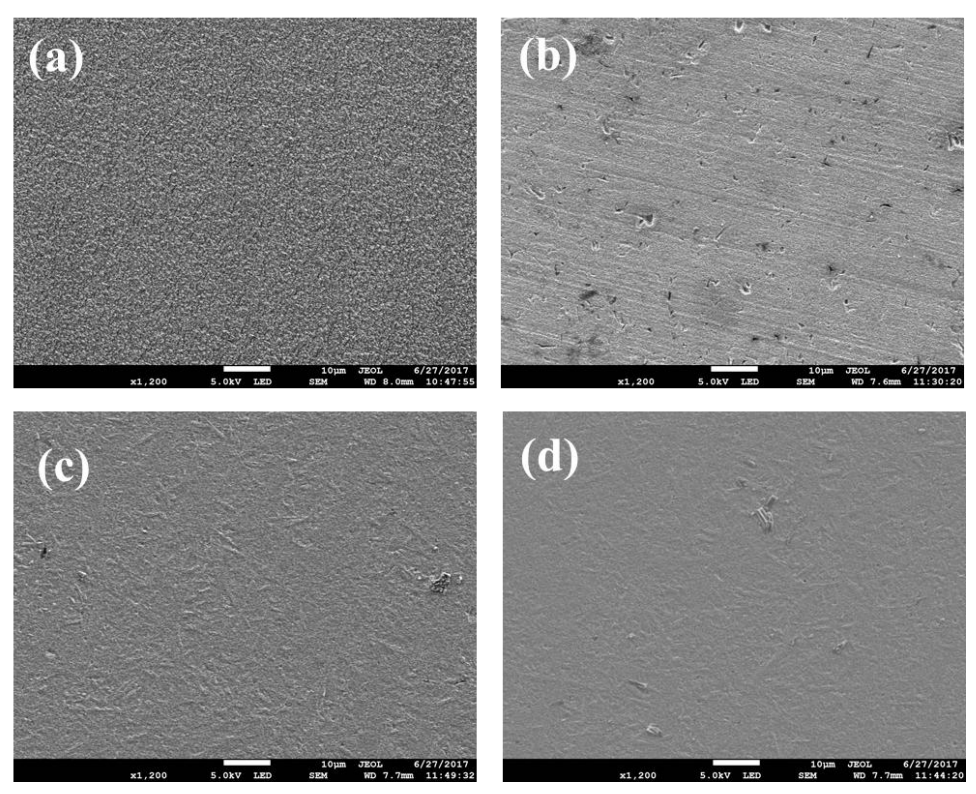

Figure 6. SEM images of copper after immersion in $0.5 \mathrm{M} \mathrm{H}_{2} \mathrm{SO}_{4}$ for $32 \mathrm{~h}$. (a) blank, and with 4 mM (b) APP, (c) Br-App, (d) I-APP, respectively.

\section{Adsorption isotherm simulation}

Langmuir isotherm proved to be the most suitable mode to fit the results of electrochemical impedance data. The corresponding formula is as follows [37, 38]:

$$
\frac{\theta}{1-\theta}=K_{\mathrm{ads}} C
$$

Herein, $\theta$ means the surface coverage, $K_{\text {ads }}$ is the equilibrium constant of adsorption, and $C$ is the concentration of the inhibitor in the electrolyte. The fitted lines of inhibitors are displayed in Figure 7. The linear correlation coefficients $(R)$ all approach 1.0, indicating the good fitting of Langmuir isotherm. The standard adsorption free energy $\left(\Delta G_{\text {ads }}^{0}\right)$ can be calculated from the following equation [39]:

$$
K_{\text {ads }}=\frac{1}{55.5} \exp \left(\frac{-\Delta G_{\mathrm{ads}}^{0}}{R T}\right)
$$

where $K_{\text {ads }}$ is the reciprocal of the intercepts of the straight lines in Figure 7, $R$ is the gas constant, and $T$ is the absolute temperature. The adsorption mode was physisorption when the absolute value of $\Delta G_{\text {ads }}^{0}$ was lower than $20 \mathrm{~kJ} / \mathrm{mol}$, while the inhibitors was chemisorption when the $\Delta G_{\text {ads }}^{0}$ was higher than $40 \mathrm{~kJ} / \mathrm{mol}$ [40].

As is shown in Figure 7, the values of $\Delta G_{\text {ads }}^{0}$ are $-31.98 \mathrm{~kJ} / \mathrm{mol}$ for APP, -32.44 $\mathrm{kJ} / \mathrm{mol}$ for Br-APP and $-36.25 \mathrm{~kJ} / \mathrm{mol}$ for I-APP, respectively. We can learn from the data that pyrazolo-pyrimidine derivatives on copper possess both physisorption and 
chemisorption, and the values are all close to $-40 \mathrm{~kJ} / \mathrm{mol}$, demonstrating the erosion resistance of inhibitors.

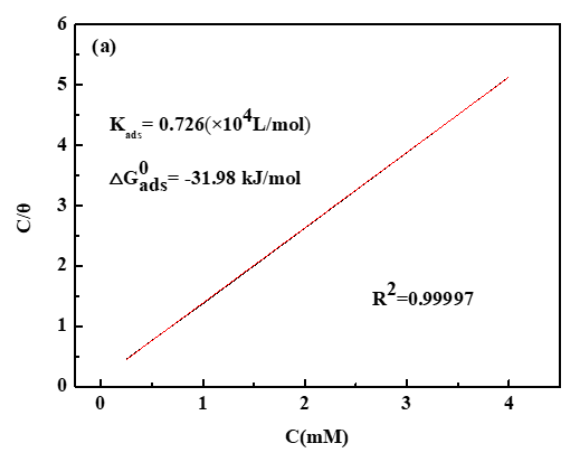

(a)

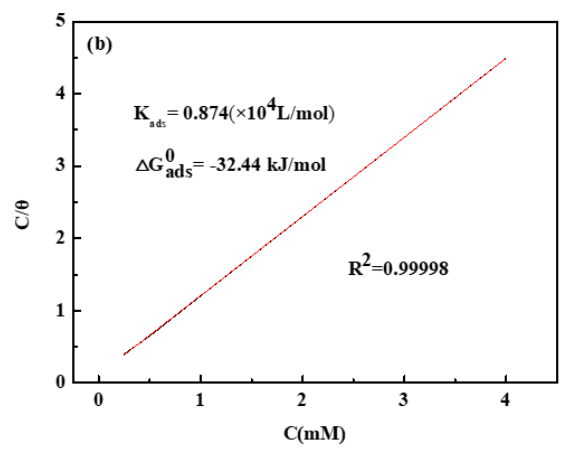

(b)

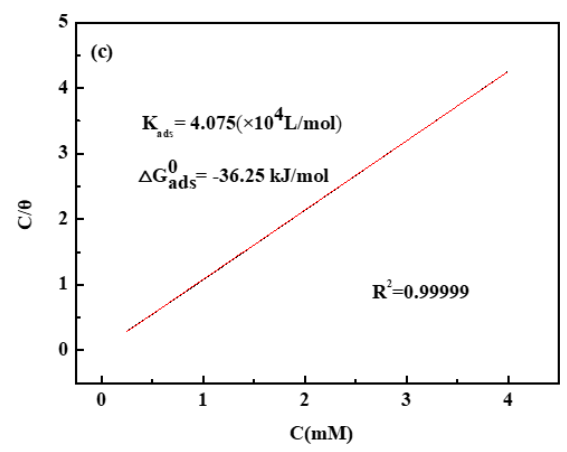

(c)

Figure 7. Langmuir adsorption line for copper in various concentrations of (a) APP, (b) $\mathrm{Br}-\mathrm{APP}$, and (c) I-APP based on the impedance measurements.

\section{Theoretical calculations}

Quantum chemical calculation can explore the relation between molecular structure and inhibition effect. Figure 8 present the optimized structures, the HOMO and LUMO density distribution of three inhibitors. Table 3 gives the values of $E_{\mathrm{HOMO}}, E_{\mathrm{LUMO}}$ and $\Delta E$, which can reflect the chemical stability of inhibitors. As known to all, the low value of $E_{\mathrm{LUMO}}$ means the electron-receiving ability of the molecule, while the high value of $E_{\mathrm{HOMO}}$ signifies the electron-donating ability of the molecule [41]. The $\Delta E$ reflects the chemical stability of inhibitors. The $\Delta E$ values of three inhibitors follows: APP < Br-APP <I-APP, which confirmed the result of experimental data.

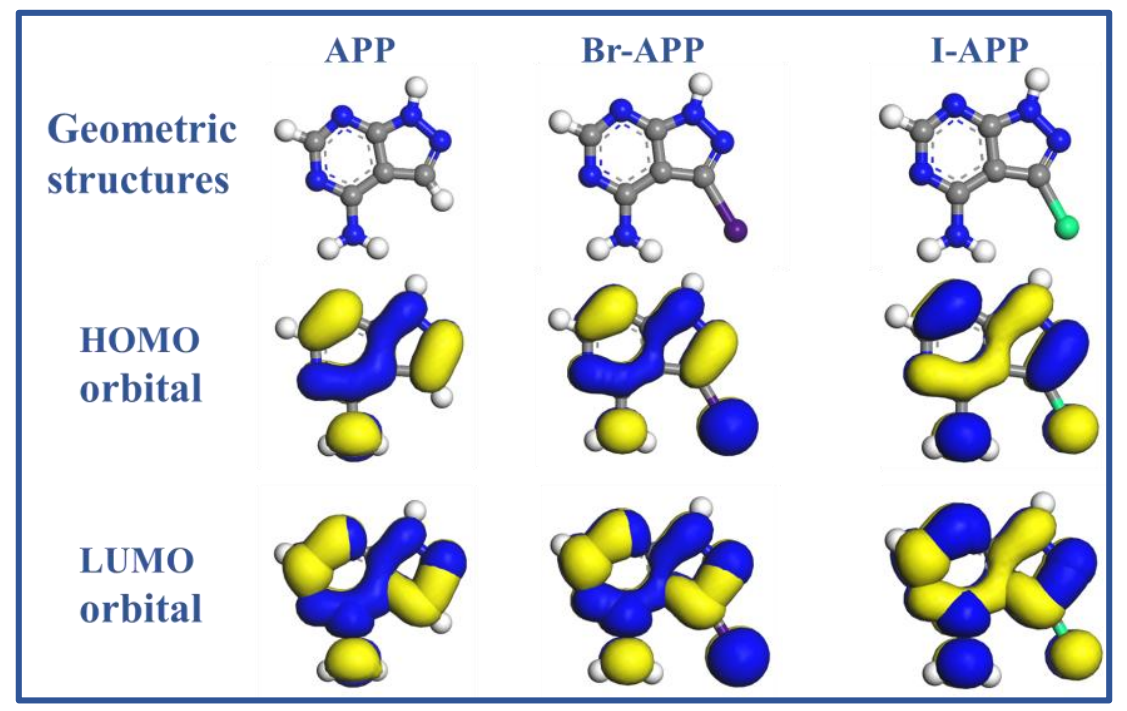

Figure 8. The optimized structures, HOMO as well as LUMO density distributions of APP, Br-APP, and I-APP. 
In addition, the dipole moment $(\mu)$ is also typical index reflecting the correlation between $\mu$ and inhibited ability. According to some authors [17,42], the low value of $\mu$ will enhance the accumulation of inhibitor on metal surface thus increase the inhibition efficiency. The calculated dipole moment values are 2.597, 1.839, and 1.767 Debye for APP, Br-APP, and I-APP, respectively. Therefore, the effect of inhibitors on copper follows: I-APP > Br-APP > APP.

Table 3. Quantum chemical parameters for three inhibitors calculated with the DFT/B3LYP/6-311++ $\mathrm{G}(\mathrm{d}, \mathrm{p})$ method

\begin{tabular}{ccccc}
\hline Species & $\boldsymbol{E}_{\text {номо }}(\mathbf{e V})$ & $\boldsymbol{E}_{\text {LUмо }}(\mathbf{e V})$ & $\boldsymbol{\Delta} \boldsymbol{E}(\mathbf{e V})$ & $\boldsymbol{\mu}($ Debye $)$ \\
\hline APP & -0.2088 & -0.0706 & 0.1382 & 2.597 \\
Br-APP & -0.2130 & -0.0788 & 0.1342 & 1.839 \\
I-APP & -0.2132 & -0.0809 & 0.1323 & 1.767 \\
\hline
\end{tabular}

Figure 9 shows the side and top views of the optimized equilibrium adsorption configurations. It is obviously that the inhibitors are absorbed in parallel on the copper through pyrazolo-pyrimidine ring whether from side or top view. This configuration can maximize the adsorption area of inhibitors on copper surface, thus minimize copper corroded by aggressive solution [43]. Therefore, the three kinds of inhibitors can reduce the attack of copper by acid. The interaction energy $\left(E_{\text {interact }}\right)$ between $\mathrm{Cu}(111)$ surface and organics can be calculated from the following equation [44]:

$$
E_{\text {interact }}=E_{\text {tot }}-\left(E_{\text {subs }}+E_{\text {inh }}\right)
$$

where $E_{\text {tot }}$ is the total energy of the simulation system, $E_{\text {subs }}$ is the energy of the copper substrate and $E_{\text {inh }}$ is the energy of the free inhibitor molecule.
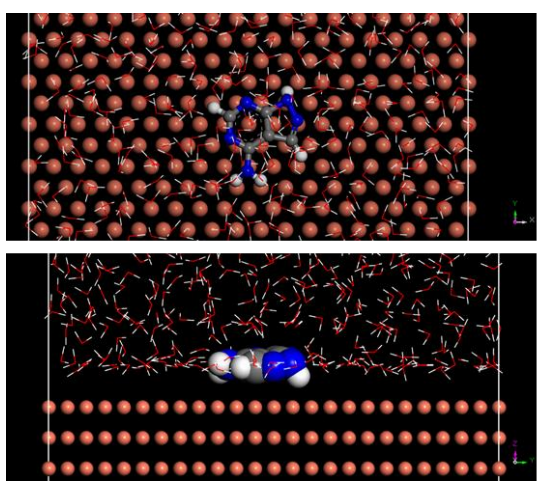

(a)
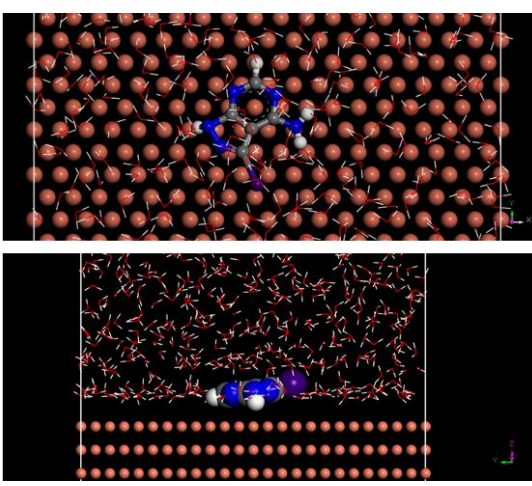

(b)
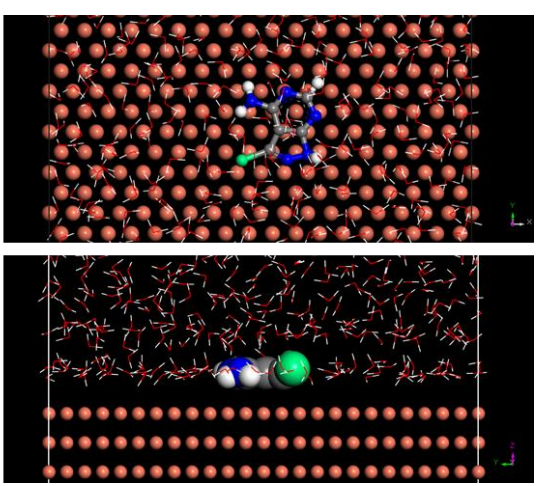

(c)

Figure 9. Side and top views of the optimized adsorption conjurations of (a) APP, (b) Br-APP, and (c) I-APP on $\mathrm{Cu}(111)$ surface. 
The interaction energies calculated from the equation are $-578.22 \mathrm{~kJ} / \mathrm{mol}$ for APP, $-553.54 \mathrm{~kJ} / \mathrm{mol}$ for Br-APP and $-560.66 \mathrm{~kJ} / \mathrm{mol}$ for I-APP. The greater absolute value of $E_{\text {interact }}$ represents the better adsorption ability of organics on copper. It is obvious that these results are not accord with the experimental data, but the calculation data are not the critical index to measure the corrosion inhibition efficiency. We are subject to favor the experimental results.

\section{Conclusions}

The performance of pyrazolo-pyrimidine derivatives as inhibitors for copper in $0.5 \mathrm{M} \mathrm{H}_{2} \mathrm{SO}_{4}$ solution was conducted by electrochemical experiments, SEM observation as well as molecular simulation calculations. The combination of experimental and theoretical techniques leads to the following conclusions:

(1) Electrochemical experiments demonstrate that pyrazolo-pyrimidine derivatives are effective mixed-type inhibitor and its inhibition efficiency increases with the increasing concentration.

(2) The SEM analyses indicate that the organics can inhibit the corrosion of copper, and the inhibited efficiency follows I-APP $>$ Br-APP $>$ APP.

(3) The adsorption of the inhibitors on the copper surface obeys the Langmuir adsorption isotherm and contains both chemisorption and physical absorption.

(4) Theoretical calculation reveals that pyrazolo-pyrimidine derivatives are adsorbed on the copper surface in a parallel way.

\section{Acknowledgements}

This research was supported by the National Natural Science Foundation of China (21706195, 21376282, 21676035), the Science and Technology Program of Guizhou Province (QKHJC2016-1149), the Guizhou Provincial Department of Education Foundation (QJHKYZ2016-105), and the Chongqing Innovation Fund for Graduate Students (CYB17022, CYB16035).

\section{References}

1. S. Miura and H. Honma, Surf. Coat. Technol., 2003, 169, 91. doi: 10.1016/S0257-8972(03)00165-8

2. K. Rasheeda, Vijaya D.P. Alva, P.A. Krishnaprasad and S. Samshuddin, Int. J. Corros. Scale Inhib., 2017, 6, 48. doi: 10.17675/2305-6894-2018-7-1-5

3. R.S. Abdel Hameed, A. El-Zomrawy, M. Abdallah, S.S. Abed El Rehim, H.I. AlShafey and N. Edin Shaher, Int. J. Corros. Scale Inhib., 2017, 6, 196. doi: 10.17675/2305-6894-2017-6-3-8

4. K.F. Khaled, Appl. Surf. Sci., 2008, 255, 1811. doi: 10.1016/j.apsusc.2008.06.030

5. A. Singha and M.A. Quraishi, J. Mater. Environ. Sci., 2015, 6, 224. 
6. P. Dohare, D.S. Chauhan and M.A. Quraishi, Int. J. Corros. Scale Inhib., 2018, 7, 25. doi: 10.17675/2305-6894-2018-7-1-3

7. Yu.I. Kuznetsov, Int. J. Corros. Scale Inhib., 2017, 6, 384. doi: 10.17675/2305-68942017-6-4-3

8. Y. Gong, Z. Wang, F. Gao, S. Zhang and H. Li, Ind. Eng. Chem. Res., 2015, 54, 12242. doi: $10.1021 /$ acs.iecr.5b02988

9. Z.Z. Tasic, M.B. Petrovic Mihajlovic, M.B. Radovanovic and M.M. Antonijevic, J. Adhes. Sci. Technol., 2017, 31, 1. doi: 10.1080/01694243.2017.1311397

10. O.A. Goncharova and A.Yu. Luchkin, Int. J. Corros. Scale Inhib., 2018, 7, 203. doi: 10.17675/2305-6894-2018-7-2-7

11. H.R. Abdel and A. hamroukh, Int. J. Corros. Scale Inhib., 2017, 6, 333. doi: 10.17675/2305-6894- 2017-6-3-8

12. I. Devesa, M.J. Alcaraz, R. Riguera and M.L. Ferrandiz, Eur. J. Pharmacol., 2004, 488, 225. doi: $10.1016 /$ j.ejphar.2004.02.015

13. K. Wong, X. Lin, K.-Y. Kwon, G. Pawin, B. Rao, A. Liu, L. Bartels, S. Stolbov and T. Rahman, Langmuir, 2004, 20, 10928. doi: 10.1021/la048208b

14. K. Zhang, B. Xu, W. Yang, X. Yin, Y. Liu and Y. Chen, Corros. Sci., 2015, 90, 284. doi: $10.1016 /$ j.corsci.2014.10.032

15. L. Guo, S.Zhu, S. Zhang, Q. He and W. Li, Corros. Sci., 2014, 87, 366. doi: 10.1016/j.corsci.2014.06.040

16. C.D. Taylor, A. Chandra, J. Vera and N. Sridhar, J. Electrochem. Soc., 2015, 162, C347. doi: 10.1149/2.0691507jes

17. N. Khalil, Electrochim. Acta, 2003, 48, 2635. doi: 10.1016/S0013-4686(03)00307-4

18. A. Brenna, F. Bolzoni, MP. Pedeferri and M. Ormellese, Int. J. Corros. Scale Inhib., 2017, 6, 59. doi: $10.17675 / 2305-6894-2017-6-1-5$

19. K.B. Wiberg, J. Comput. Chem., 2004, 25, 1342. doi: $10.1002 /$ jcc. 20058

20. R.L.C. Akkermans, N.A. Spenley and S.H. Robertson, Mol. Simul., 2013, 39, 1153. doi: 10.1080/08927022.2013.843775

21. A. Ferral, E.M. Patrito, P. Paredes-Olivera, J. Phys. Chem. B, 2006, 110, 17050. doi: 10.1021/jp0574394

22. H. Sun, P. Ren and J.R. Fried, Comput. Theor. Polym. Sci., 1998, 8, 229. doi: 10.1016/S1089-3156(98)00042-7

23. L. Antropov, Corros. Sci., 1967, 7, 607. doi: 10.1016/0010-938X(67)80036-2

24. A. Zarrouk, B. Hammouti, A. Dafali and F. Bentiss, Ind. Eng. Chem. Res., 2013, 52, 2560. doi: $10.1021 / \mathrm{ie} 301465 \mathrm{k}$

25. M.M. Solomon, H. Gerengi, S.A. Umoren, N.B. Essien, U.B. Essien and E. Kaya, Carbohydr. Polym., 2018, 181, 43. doi: 10.1016/j.carbpol.2017.10.051

26. M. Yadav, L. Gope, T.K. Sarkar, Res. Chem. Intermed., 2016, 42, 2641. doi: $\underline{10.1007 / \mathrm{s} 11164-015-2172-5}$ 
27. X.H. Li, S.D. Deng, X.G. Xie and G.B. Du, Mater. Chem. Phys., 2016, 181, 33. doi: 10.1016/j.matchemphys.2016.06.031

28. S. Nagarajan, V. Raman and N. Rajendran, J. Solid State Electrochem., 2010, 14, 1197. doi: 10.1007/s10008-009-0948-5

29. Y. Zhou, S.T. Zhang, L. Guo, S.Y. Xu, H. Lu and F. Gao, Int. J. Electrochem. Sci., 2015, 10, 2072.

30. C. Verma, L.O. Olasunkanrni, E.E. Ebenso, M.A. Quraishi and I.B. Obot, J. Phys. Chem. C, 2016, 120, 11598. doi: 10.1021/acs.jpcc.6b04429

31. Y. Qiang, S. Zhang, L. Guo, S. Xu, L. Feng, I.B. Obot and S. Chen, J. Cleaner Prod., 2017, 152, 17. doi: 10.1016/j.jclepro.2017.03.104

32. Y. Zhou, L. Guo, Z.Zhao, S. Zheng, Y. Xu, B. Xiang and S. Kaya, J. Adhes. Sci. Technol., 2018, 32, 1485. doi: 10.1080/01694243.2018.1426542

33. M. Mobin, S. Zehra and R. Aslam, RSC Adv., 2016, 6, 5890. doi: 10.1039/c5ra24630j

34. H. Lgaz, R. Salghi and I.H. Ali, Int. J. Electrochem. Sci., 2018, 13, 250. doi: 10.2964/2018.01.26

35. A.S. El-Tabei and M.A. Hegazy, J. Dispers. Sci. Technol., 2014, 35, 1289. doi: 10.1080/01932691.2013.838177

36. H. Gerengi, K. Schaefer and H.I. Sahin, J. Ind. Eng. Chem., 2012, 18, 2204. doi: 10.1016/j.jiec.2012.06.019

37. A. Dabrowski, Adv. Colloid Interface Sci., 2001, 93, 135. doi: $\underline{10.1016 / S 0001-8686(00)}$ $\underline{00082-8}$

38. H. Lgaz, R. Salghi and S. Jodeh, Int. J. Corros. Scale Inhib., 2016, 5, 347. doi: 10.17675/2305-6894-2016-5-4-5

39. A.S. Yaro, A.A. Khadom and H.E. Ibraheem, Anti-Corros. Methods Mater., 2011, 58, 116. doi: $10.1108 / 00035591111130497$

40. B. Tang, D.N. Li, F.L. Fu, Y.C. Xu, G.J. Yu and J.Y. Zhang, Ind. Eng. Chem. Res., 2012, 51, 2615. doi: 10.1021/ie201538m

41. P.M. Niamien, F.K. Essy, A. Trokourey, A. Yapi, H.K. Aka and D. Diabate, Mater. Chem. Phys., 2012, 136, 59. doi: 10.1016/j.matchemphys.2012.06.025

42. N.O. Eddy, E.E. Ebenso and U.J. Ibok, J. Appl. Electrochem., 2010, 40, 445. doi: 10.1007/s10800-009-0015-Z

43. S. Kaya, P. Banerjee, S.K. Saha, B. Tüzün and C. Kaya, $R S C A d v$., 2016, 6, 74550. doi: 10.1039/C6RA14548E

44. J.P. Zeng, J.Y. Zhang and X.D. Gong, Comput. Theor. Chem., 2011, 963, 110. doi: $\underline{10.1016 / j . c o m p t c .2010 .10 .006}$ 